\title{
Reform and Practice of Innovative Models for Electrical and Electronic Courses Based on "Internet +"
}

\author{
Fengli Jiang, Chunling Chen, Bingxin Sun* \\ Shenyang Agricultural University \\ Shenyang, China
}

\begin{abstract}
With the advent of the "Internet +" era, the "Internet +" teaching has become an important part of the teaching reform in various universities. There are many defects in traditional network teaching, for example, the teaching contents are simply copied in class to the network; the students did not participate enthusiastically; Modularity of knowledge is not high and insufficient te acher collaboration. A new teaching model for electrical and electronic courses based on "Internet +" was established. Taking electrical and electronic technology course as an example, we discussed the realization for the individualization of the "Internet + " teaching model to promote the widespread implementation of "Internet +" education. Through the comparison with the traditional network teaching model, students' scores on the online and offline teaching model based on the "Internet+" have been greatly improved, Simultaneously, learning efficiency of students and teaching quality of the courses have been improved obviously.
\end{abstract}

Keywords-“Internet +"; online and offline personalized teaching and learning; flipped classroom

\section{INTRODUCTION}

With the "Internet +" action plan integrated into the national strategy in 2015, the "Internet +" has gradually penetrated into various industries. The rise of "Internet + " is not only an opportunity for the transformation of the social and economic industries, but also an "epoch of the times" for higher education reform ${ }^{[1]}$.

The major opportunities that "Internet + " has brought to Chinese education are that it makes significant changes in curriculum, teaching, learning, evaluation, etc. It mainly reflects three aspects: Education further breaks through time and space constraints, education has become more personalized, and educational models have become more diverse. However, "Internet +" brings many benefits to education, but also brings a variety of challenges. For example, the "fast food and superficiality" of education and the indifference and alienation of the relationship between teachers, students and classmates, etc. Therefore, "Internet + education" should be an upgrade of traditional education, not a subversion of traditional education $^{[2]}$.

In this paper, we conducted in-depth research and exploration on the teaching mode of electrical and electronic courses based on the concept of "Internet +". Taking the

\footnotetext{
This work is supported by research project of teaching reform in Shenyang Agricultural University. Item Number: 2018-15, 2016-yjs-39, 2016-yjs-48.

*Corresponding author
}

courses as an example, to boldly reform and innovate in the curriculum system, teaching contents, teaching methods and practical teaching during the process of the construction of an online teaching platform based on "Internet +" curriculum group. The purpose is to form an open and efficient new teaching model meeting the needs of the times. The mode can improve students' basic scientific quality and inspire students to innovate. Moreover, it also can achieve individualized training.

\section{MAIN PROBLEMS IN TRADITIONAL NETWORK TEACHING}

\section{A. The mode of traditional network teaching is "transportation carrier + content", so the students are not enthusiastic to participate.}

The Internet is just a "tool" in traditional online teaching. It copies the teaching contents and teaching methods to the online platform, depending on video to explain. Teachers play the main role in the teaching process, for example, the teachers design the teaching content, and the teachers control the teaching process. The students are still in a passively accepted state; the mode carries out unified "format" learning. In addition, the traditional online teaching focuses on the evaluation of student learning results. It cannot record and analyze the learning process. It does not help teachers accurately analyze students' learning effects and difficulties; it is difficult to develop personalized learning for students ${ }^{[3]}$.

\section{B. Teaching content is not fully divided into small modules according to knowledge points, which affect the effect of online learning.}

According to the cognitive characteristics and learning patterns of students in pedagogy, the best time period for students to learn is the first 10 minutes or so. However, most of the excellent course teaching videos take up to 45 minutes. Even if some videos are within 15 minutes, it is only a section of ultra-long video recordings that do not form independent knowledge points, so many students give up halfway.

\section{The individualization of teacher's role is not conducive to co-building and sharing of resources.}

The traditional network teaching model is often completed by a single teacher or a group of teachers, each person is responsible for some chapters. The work between them is separate. However, in the "Internet +" education era, most of 
the latest teaching methods, such as Moocs, micro-curriculum, and flipped classroom are used. These teaching methods are not one person can complete, it should be completed by a group, or even cross-border, cross-school team. Therefore, the "teacher" under the Internet thinking is not just a person, but is teaching service team.

\section{CONSTRUCT A TEACHING MODEL FOR ELECTRICAL AND ELECTRONIC COURSES BASED ON "INTERNET +"}

\section{A. Integrate high-quality resources for electrical and electronic courses to create an "Internet + " smart learning environment.}

An intelligent teaching venue was built by using Internet technology, breaking the traditional teaching mode of "a school, a classroom, a teacher, a group of students". It supports in and out of campus and class teaching, uses inquiry-based, scenario-based, and long-range collaboration scenarios. It combines virtual and real-world, online and recorded-mixed teaching methods. It is a hybrid teaching method that combines virtual and real-world, online and recorded-mixed. Teachers and students can communicate through mobile phones and computer networks anytime, anywhere.

Optimizing the curriculum structure, inspiring students to innovate and achieving individualized training are important connotations for the reform of electrical and electronic courses. In recent years, teachers in the curriculum group have created provincial-level resource sharing courses such as "Digital Electronics Technology”, "Circuit Theory”, and school-level quality courses "Analog Electronic Technology”, "Electrical and Electronic Technology". In addition, the "Electrical and Electronic Technology" and "Analog Electronic
Experimentation Teaching Tool” network teaching courseware won the first prize and outstanding award in the national multimedia courseware competition respectively. Therefore, the curriculum group has accumulated a large number of high-quality teaching resources. These high-quality resources in the "Internet +" learning platform can create a high-quality learning environment for students with relaxed, autonomous, and research-based learning. It effectively improved the quality of teaching and promoted the ability of students' innovative thinking and innovative practice.

\section{B. Implement the reform of the traditional network teaching} model and build a personalized online and offline teaching model.

The course group designed an online and offline combination of "Internet +" teaching mode, learning from the advantages of Moocs and flipped classroom. This teaching mode is based on a combination of personalized and collaborative teaching methods. There are two methods, one is independent learning and the other is collaborative learning. The first one respects the individual's study habits and interest in learning, and the other one can form collaborative groups based on different cognitive abilities. On the one hand, the teaching mode allows students to perform hierarchical progressive learning based on their abilities. On the other hand, it allows students to learn from each other's strengths and promote emotional communication among students, which can inspire students' motivation for learning to achieve active learning. In this process, students can acquire learning experiences and knowledge that suit their needs. The teaching mode is shown in Fig.1.

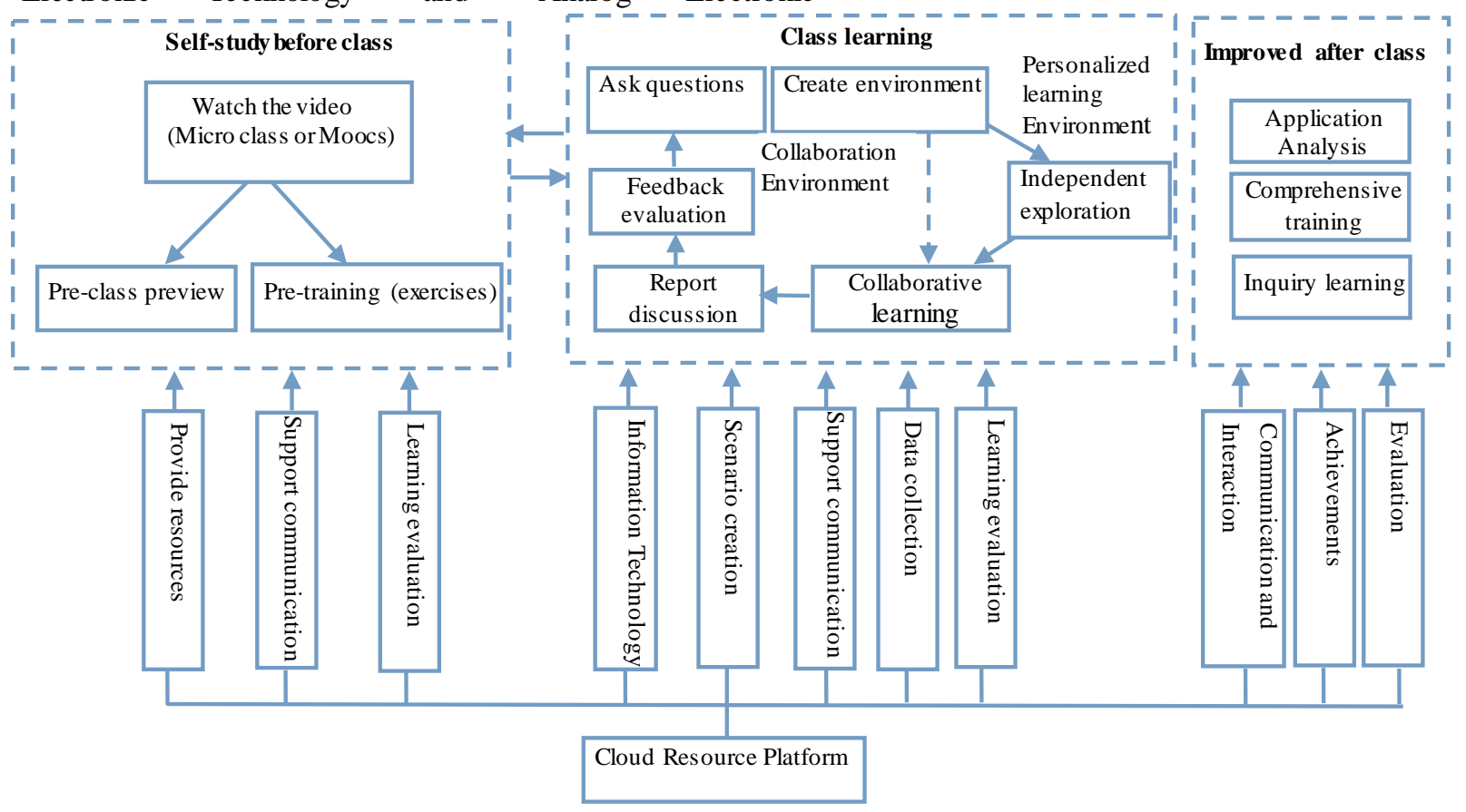

Fig. 1. Teaching mode based on "Internet+"

The teaching mode based on "Internet +" mainly includes four major parts:
1) Self-study before online class

First of all, students learn the theoretical knowledge on the Internet through teachers' pre-recorded teaching videos, and 
then prepare for class discussion through training and self-testing.

\section{2) Offline classroom learning}

In classroom, flipped classroom is usually used for teaching, focusing on discussion, practice, application and inquiry, Teachers throw out multiple teaching-related learning tasks or discussion topics, students choose independent inquiry learning or collaborative learning according to their learning ability. The collaboration team is usually composed of 3 to 5 students. In this process, teachers conduct individualized instruction, students show learning results and conduct communication between students and groups.

\section{3) Improved after class}

After the class, teachers set tasks to expand students' knowledge and improve their learning ability. Students upload learning process materials through the learning platform. Teachers use the materials submitted by the students to conduct online discussions and score.

\section{4) Feedback evaluation}

The teacher evaluates the student's learning process in stages, accumulates individual student learning status and result data, then conducts individual learning analysis through big data. Through the analysis results, we will continue to formulate learning plans, promote the accumulation of personal learning experience, and ultimately improve students' ability to study independently and collaboratively.

\section{Instructional content fragmentation design and reconstruction}

Electrical and electronic technology courses are a combination of digital electronics, analog electronics, circuit theory and other courses. Therefore, the characteristics of the course are more content and less class hours. In this situation, the course group took electrical and electronic technology courses as an example to select typical knowledge points to further fragmented and make micro lessons or Moocs for no more than 10 minutes.

\section{Create new model of "teaching" and "learning" using big data analysis and cloud computing}

Based on the "Internet +" teaching process, a large amount of data will be produced, including teacher guidance records, students watching video, completing assignments and participating in discussions, etc. Through these data teachers will develop personalized learning programs for students. With the development of Internet technology, big data analysis technology, and cloud computing technology, students and teachers can use the platform big data analysis to judge the degree of learning and learning effects in the learning process. Teachers and students can develop personalized.

\section{STUDENT ACHIEVEMENT IMPROVED}

Compared with traditional online teaching, under the online and offline teaching mode based on "Internet + ", , students' performance can be improved. As shown in Fig.2, the average scores of traditional class students are about 69 points, and 6 students are unqualified, but the average scores based on the "Internet +" teaching are about 82 points, and only one students is unqualified.

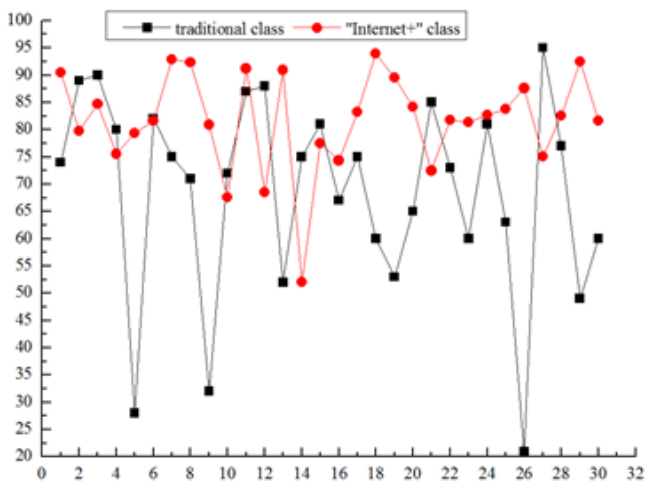

Fig. 2. Student performance comparis on between the two teaching mode

\section{CONCLUSIONS}

In the "Internet +" era, new modes of education can truly achieve global sharing of quality education resources. The course group will make full use of the online teaching system of big data analysis and cloud computing through the construction of an "Internet +" electric and electronic curriculum innovation model. Through the perfect combination of online teaching and individual creativity of the teachers, the course will enable the "Internet + Education" has truly become a booster for improving the quality of teaching, forming a teaching system with its own characteristics, and laying a solid foundation for the study and subsequent development of professional courses for all professional students.

\section{REFERANCES}

[1] YANG Zhengshu, Xu Jihui. "Research Online and Offline Integrated “Internet +” Personalized Teaching Model” [J].Chinese Vocational and Technical Education, vol.5,pp.73-78,2016.(In Chinese)

[2] YANG Tianming, YANG Tianshu. "The Adjustment and Improvement of "Internet +" Based Cross-registration Credit" [J]. Modern education management, vol.11, pp.55-58, 2015. (In Chinese)

[3] HE Yunliang. "The Impact of "Internet +" on Universities and Their Reconstruction” [J]. Journal of Qujing normal university,2015,34 (3): 58-60.(In Chinese) 